\title{
HYDRAULICS RESEARCH STATION, WALLINGFORD
}

"W ERE water a perfectly non-viscous inelastic fluid, whose particles, when in motion, always followed sensibly parallel paths, hydraulics would be one of the most exact of the sciences. But water satisfies none of these conditions, and the result is that in the majority of cases brought before the engineer, motions and forces of such complexity are introduced as baffle all attempts at a rigorous solution."

These words, written in 1908 by the late Prof. A. H. Gibson, might still serve as a raison d'être for the science of experimental hydraulics and for the large research stations at (for example) Delft, Vicksburg, Grenoble and Wallingford. Such stations are largely concerned with problems in free-surface hydraulics; but when one expresses this academic phrase in terms of water-supply, flood prevention, and sea defences, its impact on everyday life becomes apparent. One needs only to think of drought at any time or place, the catastrophic floods at Lynmouth, or the seiches of the North Sea in 1953.

So much for the reality of the problems demanding experimental study. But the cost of experimentation on the full scale is generally too high in money and, perhaps, in lives. Thus, most of this laboratory work is scaled down in space and time, so that the accuracy of the results depends on the degree of dynamical similarity achieved.

Hydraulics Research $1961^{*}$ embodies the annual report of the Hydraulics Research Board and the report of the Director of Hydraulics Research, and in 90 pages summarizes the work of the Hydraulics Research Station, Wallingford, for the year. There is a brief section on hydrological research, an activity to be developed considerably after the attachment

* Department of Scientific and Industrial Research. Hydraulics Research 1961: The Report of the Hydraulies Research Board with the Report of the Director of Hydraulics Research. Pp. iv $+96+8$ plates.
(London: H.M.S.O., 1962.) 78 . net. to the Station of a special Hydrological Research Unit. This unit is expected to concern itself particularly with the problem of rainfall and run-off in natural catchments. Such a development, clearly of national importance, will be widely welcomed. Much of the hydraulic work undertaken is necessarily of an ad hoc nature, in the sponsored solution of diverse practical problems. Nevertheless, there is evidence of a fundamental approach, for example, to the question of dynamical similarity in sediment transport, and again in the study of vortices.

It is stated that about one-half of the sponsored schemes originate overseas, so that the Station has already attained a measure of international recognition: its work, in fact, may be compared with that of the Waterloopkundig Laboratorium at Delft. The principal study-groupings are: hydraulic structures (including interesting reports on criticaldepth gauging-flumes, vortex formation at intakes, and hydro-pneumatic ship-fenders); unidirectional channel flow (including, for example, the measurement of sand transport with the aid of radioactive tracers); estuarial studies: waves and sea defences (including full-scale field studies of littoral drift, and laboratory studies of the forces exerted by waves and currents on a submarine pipe); and there are short sections on instrumentation and mechanization which might usefully be expanded in future years.

These casual references do little justice to the variety of the problems studied (in fact, no fewer than forty projects are summarized in the booklet); and the ingenuity with which they are tackled can only be appreciated after a careful reading.

There is a useful appendix listing the papers written during the year by members of the Station staff, which will enable readers to follow up particular topios in greater detail.

R. B. Whittington

\section{NUTRITIONAL PREFERENCES AMONG THE NIGERIANS}

\begin{abstract}
$\mathrm{T}$ HE West African Science Association was founded in 1953. Although its members were distributed throughout West Africa, they were predominantly resident in Ghana, where all its activities took place. It had been felt for some time that similar activities should take place in Nigeria, and, in May 1957, a circular was dispatched to as many scientists as possible resident in or near Ibadan. The replies received were mainly in favour of the formation of an Ibadan Branch of the West African Science Association though many persons preforred the formation of an independent association in Nigeria. A meeting was held on October 25, 1957, at which it was agreed that an organization to bring scientists together should be formed in Nigeria and should, if possible, be associated with the West African Science Association. This was later agreed, and the inaugural meeting of the Association was held in December 1958. The Proceedings of the Association have now been published, the first volume covering the first three years of its existence*.
\end{abstract}

* Science Association of Nigeria. Proceedings, Volumes 1-3, 19581960. Edited by Dr. B. Hopkins. Pp. 78. (Ibadan : Science Association of Nigeria, 1962.) $58.6 d$.
It contains summaries of many important articles, among them being one by Dr. W. R. Stanton of the Ministry of Agriculture, Regional Research Station, Samaru, Zaria, dealing with future changes in preference among Nigerian peoples for locally grown foodstuffs.

Preference is divisible into two types-rational and irrational. The author suggests that the study of the 'irrational' causes of preferences is equally important to that of the study of 'rational' causes. These may be listed as follows:

Irrational factors (namely, those ethnobotanically or animistically developed or a result of the cultural development of the community): (1) religious dictates; (2) animistic taboos; (3) archaic survivals of the eco-biological evolution of society; $(4)$ traditional mothods of preparations and uses; (5) prestige and status value; (6) attractiveness (in the sense that attractiveness can be the result of conditioning).

Rational factors: (1) availability and price; (2) palatability alone and with other foods (palatability, however, is subject to conditioning); (3) ease of culture, harvesting, preparation, storage, handling and marketing, yielding ability, appropriate develop- 
mental time in relation to climate, soil and water; (4) use of the plant as a whole (gross as distinct from net utility).

Stanton cites examples of the operation of these various types of preference particularly within and between different types of cereal grown in Nigeria. In studying the variation within and between the food crop species in a country, correlation with the biological factors (a convenient index for which is the ecological zone) is incomplete and a useful stratification is provided by maps showing the cultural units of Nigeria such as those defined previously by Buchanan and Pugh. The author compares interaction with the ecological zone of the strongly developed 'sorghum' culture of the savannas of West Africa with the development of grain cultures in equivalent zones in East Africa.

He suggests that present observed preference should not be the sole means of determining the development policy for food crops (species and type), but that account should be taken of the trend of preference as shown in more developed countries, of the weakening of religious ties and tribal taboos and of the increasing awareness of the urban elements of the community of the 'expressed preference' in other countries.

Lack of accurate statistics on food crop production of less-developed territories is becoming of increasing concern and the need for more data prior to development planning has been stressed by the Food and Agriculture Organization. This lack of data applies to Nigeria. Nigeria is favourably placed at present in respect of potential productivity in relation to the present population. This is a general situation, but signs of over-population, at present levels of agriculture, are already apparent in parts of the Eastern Region and Katsina and Sokoto Provinces in the Northern Region. It is also shown that the mean rate of population increase was approximately 2 per cent per annum. This figure is higher than that of any other West of Equatorial African territory.

If such a rate of increase is maintained without a concomitant rate of increase of productivity (which postulate demands a higher rate of increase of productivity than at present), it would vitiate any predictions of changes in the consumption of food crops based on comparison with that of more developed countries, since opportunities to develop a balanced, highly productive, high plane of nutrition agriculture would be superseded.

Other partially developed countries differ in their attitude to the awareness of a close approach to saturation-levels of population, and Stanton contrasts the educational and developmental policies of India and Japan. The latter country is far in advance of others in the active control of population structure by education and birth control, and an assessment of the probable future attitude of a people to such measures is of overriding importance in predicting a country's development.

\title{
CHEMISTRY, TOXICOLOGY, PHARMACOLOGY AND MICROBIOLOGY OF A NEW ACID-STABLE PENICILLIN, RESISTANT TO PENICILLINASE (BRL.162I*)
}

\author{
By J. H. C. NAYLER, A. A. W. LONG (Chemistry), D. M. BROWN, P. ACRED (Toxicology \\ and Pharmacology), G. N. ROLINSON, F. R. BATCHELOR, SHIRLEY STEVENS \\ and R. SUTHERLAND (Microbiology)
}

Beecham Research Laboratories, Ltd., Brockham Park, Betchworth, Surrey

T

HE use of methicillin, 2,6-dimethoxyphenyl penicillin, in the treatment of infections caused by penicillinase-producing strains of staphylococci is now well established in clinical practice. Its one disadvantage is that it must be given by injection since it is unstable in acid solution and poorly absorbed from the gastrointestinal tract. This article describes a new penicillin which does not suffer from this defect, and is, moreover, active at lower concentrations than methicillin. Clinical investigations are being reported concurrently elsewhere'.

\section{Chemistry}

Acylation of 6-aminopenicillanic acid with reactive derivatives of several types of sterically hindered carboxylic acid gives penicillins which resist inactivation by penicillinase. These penicillins vary considerably in their ehemical and antibacterial properties, and a particular class which combines resistance to both penicillinase and mineral acid with useful activity against most Gram-positive bacteria consists

*'Orbenin', Beecham Research Laboratories, Limited, registered trade mark.

† 'Prostaphlin', Bristol Laboratories, Inc., registered trade mark. of 3,5-disubstituted 4-isoxazolyl penicillins (I). The preparation of two such penicillins, $B R L .1400 \dagger$ ('Oxacillin') $\left[\mathrm{I} ; \quad R=\mathrm{C}_{6} \mathrm{H}_{5}, \quad R^{\prime}=\mathrm{CH}_{3}\right]$ and its isomer, $B R L .1454\left[\mathrm{I} ; R=\mathrm{CH}_{3}, R^{\prime}=\mathrm{C}_{6} \mathrm{H}_{5}\right]$, has been described in detail ${ }^{2}$. Many other penicillins of type (I) have been prepared ${ }^{3}$ and examined, and one of them, 3-o chlorophenyl-5-methyl-4-isoxazolyl penicillin [II; BRL.1621], has been selected as the compound of choice.

$B R L .1621$ is available as the sodium salt monohydrate, which forms a colourless microcrystalline<smiles>[Y6]OC(=O)C1C(C)SC2C(NC(=O)c3c([R])noc3[R4])C(=O)ON21</smiles>

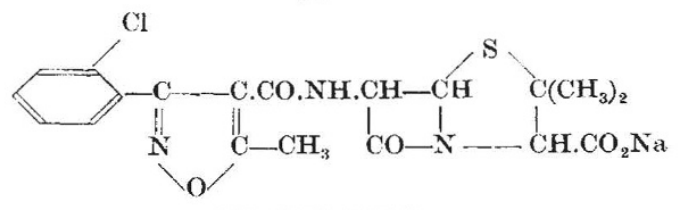

(II) BRL.1621* 